\title{
An Unusual Case of Multiple Tendinous Xanthomas Involving the Extremities and the Ears
}

\author{
Eduardo B. Bermudez ${ }^{a} \quad$ Leslie Storey $^{b}$ Sheila Mayo $^{b} \quad$ Gregory Simpson $^{b}$ \\ ${ }^{a}$ Morehouse School of Medicine, Atlanta, Ga., and ${ }^{b}$ Division of Dermatology, UCSF Fresno, \\ Fresno, Calif., USA
}

\section{Key Words}

Tendinous xanthomas · Familial hypercholesterolemia · Subcutaneous nodules ·

Hyperlipidemia

\begin{abstract}
Tendinous and subcutaneous xanthomas are nodular deposits of lipid-filled macrophages, which commonly form on the Achilles tendon, hands, feet, elbows, and knees. These nodules are frequently associated with familial hyperlipidemia, a group of diseases involving impaired cholesterol metabolism, and the accelerated development of atherosclerotic plaques. Since xanthomas may precede the diagnosis of hyperlipidemia, early identification can lead to preventative treatment that reduces the risk and morbidity of cardiovascular disease, including myocardial infarction. This case report presents a 43-year-old African-American male with multiple xanthomas involving the Achilles tendon, soles, hands, knees, elbows, and is associated with the unusual involvement of the ear.

(C) 2015 The Author(s)

Published by S. Karger AG, Basel
\end{abstract}

\section{Introduction}

Tendinous xanthomas are caused by impairment in lipoprotein regulation, which results in accumulated cholesterol deposits in the tendons, ligaments, or periosteum [1]. The nodules are most often found over the Achilles tendons, hands, and the extensor surfaces of the elbows and knees [1]. These slow-growing nodules are firm and mobile and can present with a yellowish hue [2]. As the nodules enlarge, they can cause pain, restricted joint mobility, disability, and tendon rupture $[3,4]$.

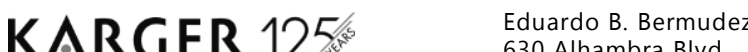


Bermudez et al.: An Unusual Case of Multiple Tendinous Xanthomas Involving the Extremities and the Ears

Tendinous xanthomas are commonly associated with familial hypercholesterolemia $(\mathrm{FH})$, an autosomal dominant disorder due to a mutation in the LDL receptor gene, which results in impaired cellular uptake of LDL [1]. However, they can rarely be seen in cerebrotendinous xanthomatosis or beta-sitosterolemia, both of which are autosomal recessive disorders [1].

Histopathologically, tendinous xanthomas are composed of accumulated foam cells (enlarged macrophages, resulting from phagocytosis of elevated LDL cholesterol in the plasma [5]), histiocytes, and lymphocytes, which infiltrate the tendon or integument. The process is similar to atherosclerotic plaque formation [6], and demonstrates that xanthomas can be a marker for cardiovascular disease.

Tendinous xanthomas in association with FH carry a 300\% increased risk of cardiovascular disease [7] as well as an increased risk for lymphoproliferative malignancies [1]. Early diagnosis and intervention can prevent the morbidity and mortality associated with these conditions. However, based on an estimated prevalence of $1 / 200$, a recent screening study suggests that $\mathrm{FH}$ is underdiagnosed as less than $1 \%$ of patients with $\mathrm{FH}$ are routinely identified [8].

\section{Case Report}

A 43-year-old African-American male presented with a 35-year history of multiple, slowly enlarging, subcutaneous nodules, which restrict his joint motion and are frequently painful. On examination, multiple ivory colored, firm, but mobile nodules overlie the dorsal aspects of the proximal and distal interphalangeal joints and multiple metacarpal phalangeal joints in the hands (fig. 1a-d). Nodules are also noted over the extensor surfaces of the knees (fig. 2a, b), Achilles tendons, right elbow (fig. 2c), sole of the feet, and the helix, scapha, and anti-helix of the ears (fig. 3a, b). He has had surgical removal of the nodules in the past, but they recur within a few years. Laboratory tests were remarkable for a total cholesterol of $518 \mathrm{mg} / \mathrm{dl}(13.4 \mathrm{mmol} / \mathrm{l})$.

\section{Discussion}

Patients who are heterozygous or homozygous for FH will have elevated cholesterol levels from birth. Homozygous patients will typically have LDL cholesterol levels over 13 $\mathrm{mmol} / \mathrm{l}$ in adulthood and $11 \mathrm{mmol} / \mathrm{l}$ in childhood. In contrast, heterozygous patients usually demonstrate LDL levels of $7.5 \mathrm{mmol} / \mathrm{l}$ or less [9]. Patients with homozygous FH manifest advanced atherosclerosis and xanthomas in childhood, often leading to death before the third decade if left untreated. Heterozygous patients for FH generally develop xanthomas in the second decade and have an increased likelihood of a cardiac event prior to the fifth decade if left untreated [9].

Tendinous xanthomas most commonly develop on the Achilles tendon, patella, and hand. Therefore, tendinous xanthomas can be confused with other growths such as rheumatoid nodules, giant cell tumors of the tendon sheath, ganglions, and sarcomas with xanthomatous changes [4]. In patients with multiple nodules, the disease may resemble Langerhans cell histiocytosis or neurofibromatosis [10]. Histologically, tendinous xanthomas differ from giant cell tumors due to a lack of round cells and a paucity of the multinucleated giant cells [4]. Sarcoma with xanthomatous changes can be distinguished by careful attention to 
Bermudez et al.: An Unusual Case of Multiple Tendinous Xanthomas Involving the Extremities and the Ears

the presence of atypical mitotic figures, osteoblastic, chondroblastic or fibroblastic extracellular matrix, and pleomorphic and hyperchromatic nuclei on biopsy [4].

The diagnosis of FH with tendinous xanthomas can be made based on examination coupled with an elevated LDL cholesterol, (frequently above the 75th percentile), elevated total cholesterol, arcus senilis, and a family history of premature cardiovascular disease [1]. If Achilles tendon enlargement is present, an ultrasound of the tendon often reveals a thickened tendon with echolucent regions [11]. The diagnosis can be confirmed by histopathology of the nodule or genetic testing.

Elevated LDL levels lead to the development of both the tendinous xanthomas and atherosclerotic plaques. Treatment is focused on decreasing LDL levels through the use of statin medications, or ezetimibe, combined with dietary modification and counseling regarding the risks of alcohol, smoking, and sedentary lifestyle [12]. For more severe cases, combination therapy with a bile acid sequestrant [13], nicotinic acid, fibrates, low-density lipoprotein apheresis [2,14], or orthotopic liver transplantation [2] may be required. However, very large tendinous xanthomas, or those that impede joint function, will typically require surgical removal with possible skin grafting [15]. The workup should include a cardiology evaluation to rule out early coronary artery disease. Xanthomas can also appear as a consequence of elevated lipid levels secondary to liver or kidney disease, bile duct obstruction, diabetes, hypothyroidism, or alcoholism [10]. Laboratory tests to rule out these conditions is recommended [12].

\section{Statement of Ethics}

The patient involved in this case report has signed an informed consent allowing the use of pictures and information in an anonymous format.

\section{Disclosure Statement}

The authors have no conflicts of interest and have not received any funding or financial consideration with respect to this article.

\section{References}

1 Zak A, Zeman M, Slaby A, Vecka M: Xanthomas: clinical and pathophysiological relations. Biomed Pap 2014;158:181-188.

2 Palacio CH, Harring TR, Nguyen NTT, Goss JA, O’Mahony CA: Homozygous familial hypercholesterolemia: case series and review of the literature. Case Rep Transplant 2011;2011:154908.

-3 Tsouli SG, Kiortsis DN, Argyropoulou MI, Mikhailidis DP, Elisaf MS: Pathogenesis, detection and treatment of Achilles tendon xanthomas. Eur J Clin Invest 2005;35:236-244.

4 Huri G, Joachim N: An unusual case of hand xanthomatosis. Case Rep Orthop 2013;2013:183018.

5 Kumar V, Abbas AK, Fausto N, Aster JC: Robbins and Cotran Pathologic Basis of Disease, ed 8. Philadelphia, Saunders Elsevier, 2010.

-6 Roy AK, Das S, Chowdhury J, Bhanja D: Tendinous xanthoma with familial hypercholesterolemia. Indian Dermatol Online J 2014;5(suppl 1):S59-S60.

7 Oosterveer DM, Versmissen J, Yazdanpanah M, Hamza TH, Sijbrands EJ: Differences in characteristics and risk of cardiovascular disease in familial hypercholesterolemia patients with and without tendon xanthomas: a systematic review and meta-analysis. Atherosclerosis 2009;207:311-317.

8 Nordestgaard BG, Chapman MJ, Humphries SE, et al: Familial hypercholesterolaemia is underdiagnosed and undertreated in the general population: guidance for clinicians to prevent coronary heart disease: consensus statement of the European atherosclerosis society. Eur Heart J 2013;34:3478-3490. 


\section{Case Reports in Dermatology}

\begin{tabular}{l|l}
\hline Case Rep Dermatol 2015;7:340-344 \\
\hline DOI: $10.1159 / 000441711$ & $\begin{array}{l}\text { (c) 2015 The Author(s). Published by S. Karger AG, Basel } \\
\text { www.karger.com/cde }\end{array}$ \\
\hline
\end{tabular}

Bermudez et al.: An Unusual Case of Multiple Tendinous Xanthomas Involving the Extremities and the Ears

9 Farnier M, Bruckert E: Severe familial hypercholesterolaemia: current and future management. Arch Cardiovasc Dis 2012;105:656-665.

10 Reichwaldt I, Zustin J, Wenke K, Ridderbusch I: Differential diagnosis of tendon tumors: xanthomas caused by hyperlipidemia in children. J Pediatric Surg 2010;45:e9-e12.

-11 Junyent M, Gilabert R, Zambón D, Núñez I, Vela M, Civeira F, et al: The use of Achilles tendon sonography to distinguish familial hypercholesterolemia from other genetic dyslipidemias. Arterioscler Thromb Vasc Biol 2005;25:2203-2208.

12 NICE Clinical Guidelines: Identification and management of familial hypercholesterolaemia. London, Royal College of General Practitioners, 2008, No 71.

13 Sonnett T, Robinson J, Milani P, et al: Role of colesevelam in managing heterozygous familial hypercholesterolemia in adolescents and children. Adolesc Health Med Ther 2010;1:53-60.

14 Ohshito T, Shimabukuro T, Sunagawa M, Ohta T: An 11-year-old boy with familial hypercholesterolemia showing multiple xanthomas and advanced atherosclerosis, who responded to lipid-lowering therapy using statin. J Atheroscler Thromb 2009;16:698-701.

15 Ahn J, Chun T, Lee S: Nodular excision for painful localized Achilles tendon xanthomas I type II hyperlipoproteinemia: a case report. J Foot Ankle Surg 2011;50:603-606.
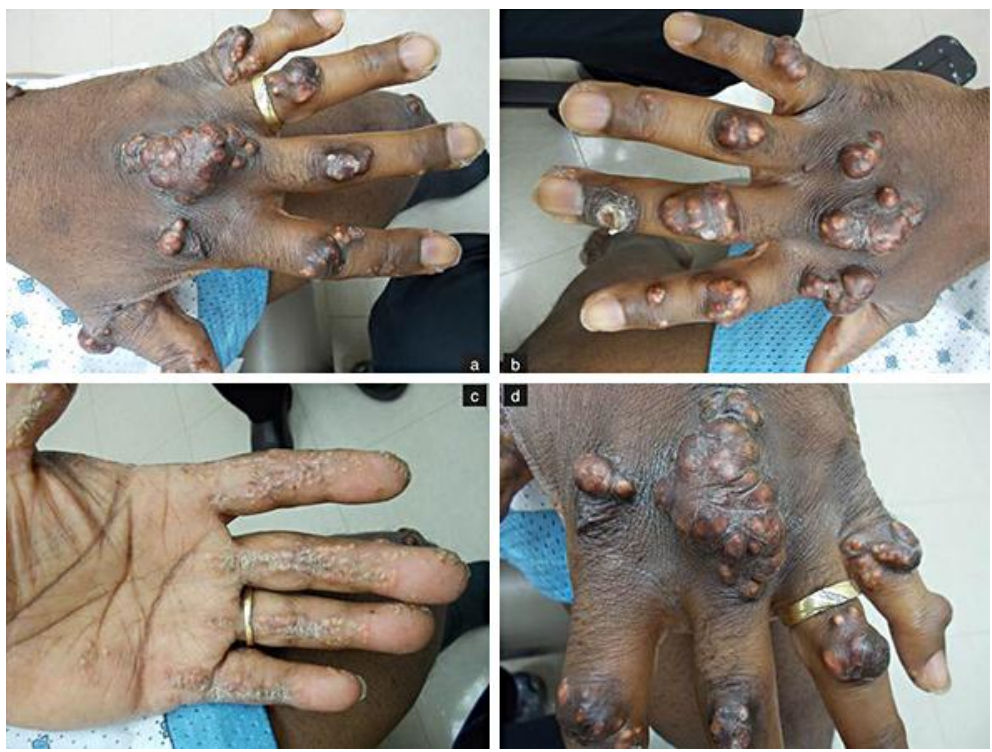

Fig. 1. Tendinous xanthomas overlying the joints of the hands. a Left hand. b Right hand. c Left palm d Close-up of the left hand. 


\section{Case Reports in Dermatology}

\begin{tabular}{l|l}
\hline Case Rep Dermatol 2015;7:340-344 \\
\hline DOI: 10.1159/000441711 & $\begin{array}{l}\text { (c) 2015 The Author(s). Published by S. Karger AG, Basel } \\
\text { www.karger.com/cde }\end{array}$ \\
\hline
\end{tabular}

Bermudez et al.: An Unusual Case of Multiple Tendinous Xanthomas Involving the Extremities and the Ears
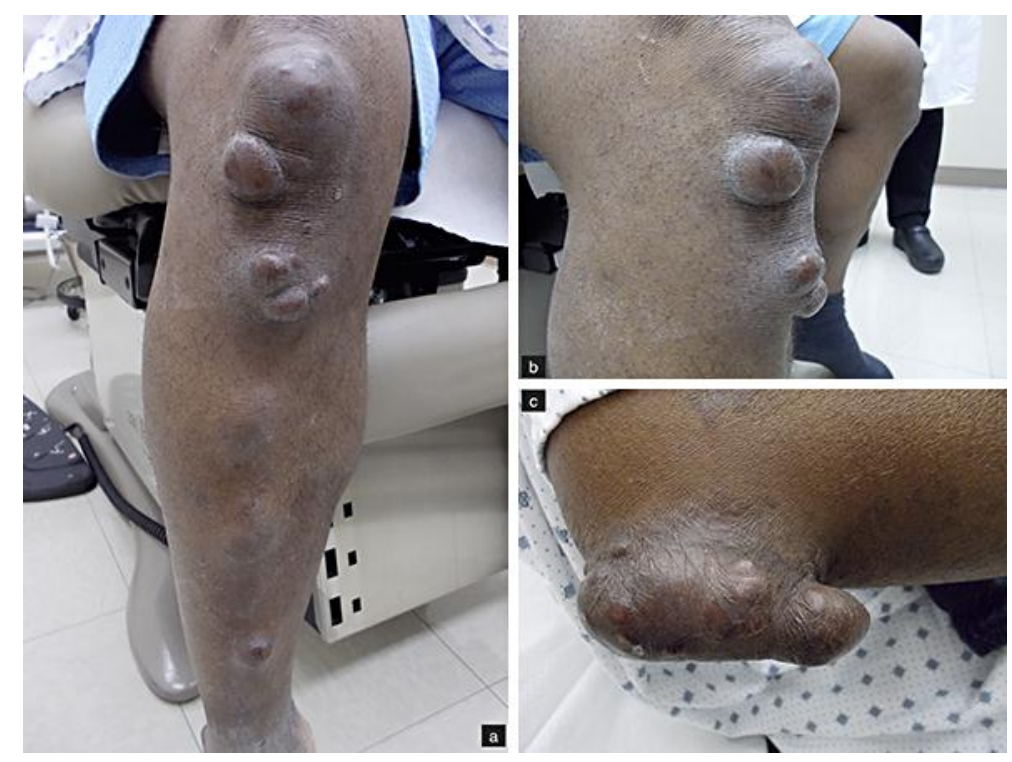

Fig. 2. Tendinous xanthomas overlying the joints of the legs and arms. a Right leg. b Right knee. c Right elbow.
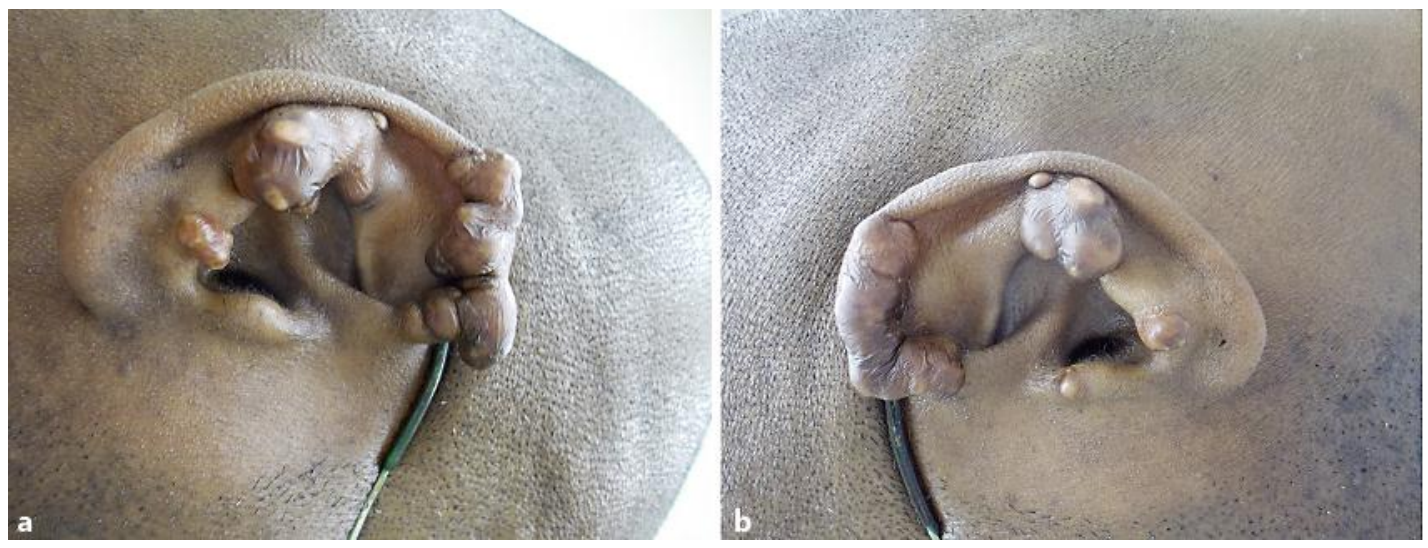

Fig. 3. Ear involvement with xanthomas. a Left ear. b Right ear. 